\title{
Reinforcement of nitrile rubber by in situ formed zinc disorbate
}

\author{
B. C. Guo ${ }^{1,2^{*}}$, F. Chen ${ }^{1}$, W. W. Chen 1 , Y. D. Lei ${ }^{1}$, D. M. Jia ${ }^{1}$ \\ ${ }^{1}$ Department of Polymer Materials and Engineering, South China University of Technology, Guangzhou 510640, China \\ ${ }^{2}$ State Key Laboratory of Pulp and Paper Engineering, South China University of Technology, Guangzhou 510640, China
}

Received 2 April 2010; accepted in revised form 16 May 2010

\begin{abstract}
Zinc disorbate (ZDS) was in situ formed by the reaction between sorbic acid (SA) and zinc oxide ( $\mathrm{ZnO})$ in nitrile rubber (NBR). The effects of SA amount on the curing characteristics, crosslink density and mechanical properties of peroxide-cured NBR were studied. The results showed that ZDS was generated mainly during the rubber vulcanization, rather than the open mill compounding phase. The results from the crosslink density determinations showed that the formation of ZDS significantly increased the ionic bond content in the vulcanizates. In addition, the formation of ZDS greatly enhanced the mechanical properties of NBR vulcanizates. The modulus, tensile strength, tear strength and hardness were found to be increased with the loading of ZDS. Preheating the compounds before compression moulding was beneficial to the formation of ZDS, and consequently the increases in mechanical properties. At 40 parts per hundred rubber (phr) of SA and $16 \mathrm{phr} \mathrm{ZnO}$, five to six folds of tensile strength and tear strength of the neat NBR vulcanizate were achieved. Transmission electron microscopy (TEM) results confirmed the nano-dispersion structure of the polymerized ZDS in the NBR matrix.
\end{abstract}

Keywords: reinforcements, nitrile rubber, sorbic acid, zinc oxide

\section{Introduction}

Carbon black, silica and clay have already been used as effective reinforcements of rubbers for different purposes [1-4]. Ionic clusters have also been proved to be reinforcing towards rubbers $[5,6]$. Since highly filled zinc dimethacrylate (ZDMA) reinforced hydrogenated nitrile rubber (HNBR) with high tensile and excellent abrasion resistance was developed by Zeon Chemicals, reactive metal carboxylates have been tried as novel rubber reinforcements for their good dispersion properties and reinforcing effect [7-18]. Zhang and coworkers [11-14] investigated the in situ formation of ZDMA and magnesium dimethacrylate (MDMA) by the reaction of zinc oxide $(\mathrm{ZnO})$, magnesium oxide $(\mathrm{MgO})$ with methacrylic acid (MAA), and discussed the reinforcing effect of the resultants on the rubbers. Lu et al. [16] investigated the morpholo- gies of ZDMA particles in various elastomers before and after vulcanization by scanning electron microscopy (SEM) and transmission electron microscopy (TEM). During compounding, the size of ZDMA particle was reduced and could even form nano-scale structures, depending on the shear stress during mixing. The authors observed two structures in the vulcanizates: a micron-scale dispersion of residual ZDMA particles and a nanoscale dispersion of poly-ZDMA aggregates. Multiple mechanisms for the reinforcement of rubbers by reactive metal carboxylates were involved in the systems [11, 14, 17]. First, during the rubber vulcanization, the unsaturated metal carboxylates could be polymerized (crosslinking) to form the reinforcing nanoparticles via free radical mechanism. Furthermore, the unsaturated salts could be grafted onto rubber chains during rubber vulcaniza- 
tion. Therefore reinforced rubber network with very tight interfacial bonding was formed in these systems. As a consequence, the mechanical properties of these rubber compounds were extraordinarily higher than those filled with traditional fillers such as carbon black or silica.

In view of the high cost of metal (meth)acrylates and the corrosive nature of (meth)acrylic acid, exploring alternative reactive metal carboxylates was still necessary. Recently, we demonstrated that sorbic acid (SA), a common food preservative, was very effective in promoting the interfacial properties of silica or halloysite reinforced rubber and it is revealed that zinc disorbate (ZDS) was in situ formed in those systems [19-21]. In the present work, we attempted to use the in situ formed ZDS as the sole reinforcing agent for nitrile rubber (NBR). The formation regularity of ZDS, curing characteristics and reinforceablity of the formed ZDS, were investigated.

\section{Experimental}

\subsection{Materials}

NBR with acrylonitrile content $40 \%$, was manufactured by Jilin Chemical Industry Company, Jilin, China. SA with purity of $98 \%$ was obtained from Ningbo Wanglong Group Co., Ltd, Zhejiang, China. ZnO was analytical grade from Tianjin Fuchen Chemical Reagent Co., Ltd, Tianjin, China. Stearic acid was chemical grade from Shanghai Lingfeng Chemical Reagent Co., Ltd, Shanghai, China. 2-mercaptobenzimidazole (MB) was chemical grade from Guangzhou Chuangsheng Chemical Material Co., Ltd, Guangdong, China. Dicumyl peroxide (DCP) was chemical grade from Sinopharm Chemical Reagent Co., Ltd, Shanghai, China. Acetone was analytic grade from Guangzhou Dongfanghong Chemical Plant, Guangdong, China.

\subsection{Preparation of NBR/ ZDS composites}

The compositions of the rubber compounds were tabulated in Table 1. The molar ratio of $\mathrm{ZnO} / \mathrm{SA}$ was kept at $1 / 1.8$ in all samples except for the control sample. $\mathrm{ZnO}$ was slightly excessive as stearic acid will react with zinc oxide to form zinc stearate. NBR and SA were compounded with rubber additives with a two-roll mill at room temperature. For comparison, a group of the compounds excluding
Table 1. Compositions of NBR/ZDS nanocomposites ${ }^{a}$

\begin{tabular}{|l|c|c|c|c|c|c|}
\hline Sample code & $\mathbf{1}$ & $\mathbf{2}$ & $\mathbf{3}$ & $\mathbf{4}$ & $\mathbf{5}$ & $\mathbf{6}$ \\
\hline NBR & 100 & 100 & 100 & 100 & 100 & 100 \\
\hline Stearic acid & 1 & 1 & 1 & 1 & 1 & 1 \\
\hline $\mathrm{MB}$ & 1.5 & 1.5 & 1.61 & 1.76 & 1.9 & 2.05 \\
\hline $\mathrm{ZnO}$ & 1 & 1 & 4 & 8 & 12 & 16 \\
\hline SA & 0 & 2.5 & 10 & 20 & 30 & 40 \\
\hline DCP & 1 & 1 & 1.07 & 1.17 & 1.27 & 1.37 \\
\hline
\end{tabular}

a NBR: nitrile rubber; ZnO: zinc oxide; $\mathrm{MB}$ : 2-mercaptobenzimidazole; SA: sorbic acid; DCP: dicumyl peroxide

DCP were placed in an oven at $120^{\circ} \mathrm{C}$, and then evacuated to eliminate possible oxidation of the compounds. All the compounds were heat treated for $15 \mathrm{~min}$ in the vacuum oven before vulcanization. DCP was then included into the heat treated samples by re-compounding the samples. Then all the compounds were press-cured to a $1 \mathrm{~mm}$ thickness sheet at $170^{\circ} \mathrm{C}$ vulcanization time and then cut into specimens for measurements. The vulcanization time was determined at $170^{\circ} \mathrm{C}$ by U-CAN UR2030 vulcameter, Taipei, Tianwan.

\section{Characterizations}

\subsection{Differential scanning calorimetry (DSC)}

To explore the reaction between $\mathrm{ZnO}$ and SA during simple heating, the mixture of $\mathrm{ZnO} / \mathrm{SA}$ (molar ratio of $1 / 2$ ) was prepared by vigorous mixing. The reaction of the mixture under heating was studied by DSC. The mixture was sealed in DSC pan and the heat flow during heating was recorded. The heat flow of the sample was shown in Figure 1, which indicated that there were several stages for the reaction between $\mathrm{ZnO}$ and $\mathrm{SA}$. We chose three upper temperatures at 60,90 and $120^{\circ} \mathrm{C}$ for preparing three treated samples at different degrees of con-

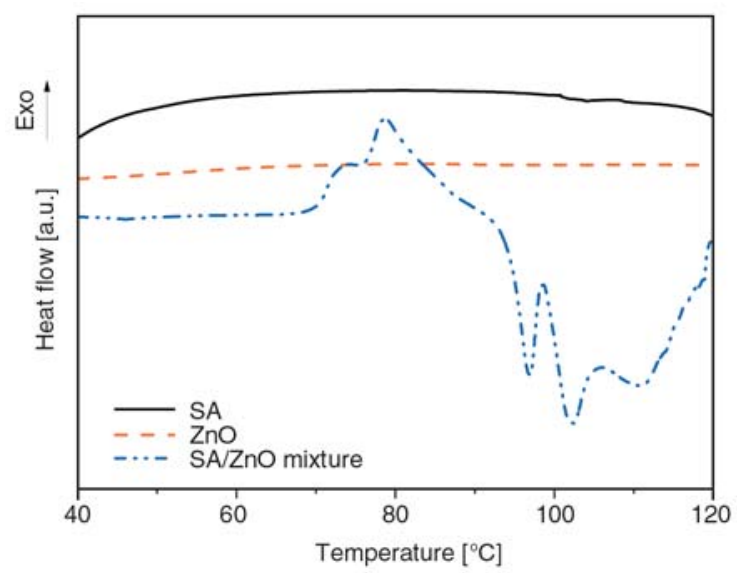

Figure 1. DSC graph of the $\mathrm{SA}, \mathrm{ZnO}$, and $\mathrm{SA} / \mathrm{ZnO}$ mixture 
version. When the temperature was heated to the upper temperature, the sample was quenched to stop the reaction. The three samples with upper treating temperatures at 60,90 and $120^{\circ} \mathrm{C}$ were labeled as A, B and C, respectively. All the DSC runs were conducted with a TA Q20 (New Castle, America) at a ramping rate of $2^{\circ} \mathrm{C} / \mathrm{min}$ and using nitrogen as purging gas.

\subsection{X-ray diffraction (XRD)}

The XRD of the rubber compounds, vulcanizates and the above mentioned samples of $\mathrm{A}, \mathrm{B}$ and $\mathrm{C}$ were recorded at ambient temperature on a Rigaku Dmax/III diffractometer (Rigaku Corporation, Tokyo, Japan) using a $\mathrm{CuK}_{\alpha}$ radiation $(\lambda=1.54 \AA)$. All the samples were scanned from 2 to $50^{\circ}$ with a step length of $0.02^{\circ}$.

\subsection{Determination of crosslink density}

Crosslink density was determined by the equilibrium swelling method $[10,11,17,22,23]$. The value was classified into three types, that is, covalent crosslink density $\left(V_{e 1}\right)$, ionic crosslink density $\left(V_{e 2}\right)$ and total crosslink density $\left(V_{e}=V_{e 1}+V_{e 2}\right)$. To measure $V_{e}$, samples were swollen in acetone $\left(\rho_{s}=0.788 \mathrm{~g} / \mathrm{ml}\right)$ at room temperature for $72 \mathrm{~h}$ and then removed from the solvent and the surface acetone was blotted off quickly with tissue paper. The samples were immediately weighed on an analytical balance and then dried in a vacuum oven for $36 \mathrm{~h}$ at $70^{\circ} \mathrm{C}$ to remove all the solvent and reweighed. The volume fraction of NBR in the swollen gel, $V_{r}$, was calculated by Equation (1) [22]:

$$
V_{r}=\frac{m_{0} \phi \frac{1-\alpha}{\rho_{r}}}{m_{0} \phi \frac{1-\alpha}{\rho_{r}}+\frac{m_{1}-m_{2}}{\rho_{s}}}
$$

where $m_{0}$ is the sample mass before swelling, $m_{1}$ and $m_{2}$ are sample masses before and after drying, $\phi$ is the mass fraction of rubber in the vulcanizate, $\alpha$ is the mass loss of the gum NBR vulcanizate during swelling, and $\rho_{r}$ and $\rho_{s}$ are the rubber and solvent density, respectively.

The elastically active network chain density, $V_{e}$, which was used to represent the whole crosslink density, was then calculated by the well-known Flory-Rehner equation (Equation (2)) [23]:

$$
V_{e}=\frac{\ln \left(1-V_{r}\right)+V_{r}+\chi V_{r}^{2}}{V_{s}\left(V_{r}^{\frac{1}{3}}-\frac{V_{r}}{2}\right)}
$$

where $V_{r}$ is the volume fraction of the polymer in the vulcanizate swollen to equilibrium and $V_{s}$ is the solvent molar volume $(73.4 \mathrm{ml} / \mathrm{mol}$ for acetone at room temperature). $\chi$ is the NBR-acetone interaction parameter and is taken as 0.349 calculated according to reference $[24,25]$.

As mentioned above, the vulcanizates contained both covalent and ionic crosslinks, so it was significant to distinguish ionic crosslink density from covalent crosslink density. It was documented that rubber swollen in an acidic solution can destroy the ionic crosslinks [10, 11, 17]. To determine covalent crosslink density, samples were swollen again in the mixture of acetone and dichloroacetic acid for $120 \mathrm{~h}$ to destroy ionic crosslinks, then swollen in pure acetone for $72 \mathrm{~h}$ and weighed, and then vacuum dried and reweighed. $V_{r 1}$ calculated by Equation (1) represents the extent of swelling after destroying ionic crosslinks. $V_{e 1}$ calculated by Equation (2) represented the covalent crosslink density. $V_{e 2}$ calculated by subtracting $V_{e 1}$ from $V_{e}$.

\subsection{Morphological observations}

The specimens were ultramicrotommed into thin pieces of about $120 \mathrm{~nm}$ thickness with a Leica EM UC6 (Wetzlar, Germany). Then the TEM observations were done using a Philips Tecnai 12 TEM (Amsterdam, Netherlands) at an accelerating voltage of $30 \mathrm{kV}$.

\subsection{Mechanical properties}

Tensile tests including 100\% modulus, tensile strength, elongation at break and permanent set were performed following ASTM D412 using U-CAN UT-2060 (Taipei, Taiwan) instrument, and the cross head speed was $500 \mathrm{~mm} / \mathrm{min}$. Shore A hardness was performed following DIN 53505 using a XY sclerometer (Shanghai, China). 


\section{Results and discussion \\ 4.1. Formation of ZDS during rubber vulcanization}

The DSC graph of $\mathrm{ZnO}$, SA and the model $\mathrm{ZnO} / \mathrm{SA}$ mixture is shown in Figure 1. It is clear that for $\mathrm{ZnO}$ and $\mathrm{SA}$, there is no exothermic or endothermic peak appears during the process, indicating there is no reaction or phase change occurring in them in the tested temperature range. For the model $\mathrm{ZnO} /$ SA mixture, however, there is an exothermic peak around $80^{\circ} \mathrm{C}$ and endothermic peaks between 90 and $120^{\circ} \mathrm{C}$. The exothermic peak and the endothermic regions indicate a complicated reaction process between $\mathrm{ZnO}$ and SA takes place during simple heating of the mixture. The XRD patterns of $\mathrm{ZnO}$, SA and the model samples with different upper heat treating temperature were recorded. One can see in Figure 3 the characteristic diffraction peaks of SA at 13.5, 15.1, 26.9, 28.9 and $31.8^{\circ}$ and the characteristic diffraction peaks of $\mathrm{ZnO}$ at 37.1, 39.8 and $41.6^{\circ}$. For sample A, the XRD pattern is the overlay of $\mathrm{XRD}$ patterns for $\mathrm{ZnO}$ and $\mathrm{SA}$, suggesting that no reaction takes place between $\mathrm{ZnO}$ and SA below $60^{\circ} \mathrm{C}$. For sample B, although the diffractions for $\mathrm{SA}$ are still present, the diffraction peaks of $\mathrm{ZnO}$ disappear. In addition, a new peak appears around $7.8^{\circ}$, which is, however, not identical to the diffraction of ZDS which evolved from basic zinc carbonate and SA [19]. In the XRD pattern of sample $\mathrm{C}$, it can be seen that the diffractions for SA and $\mathrm{ZnO}$ completely disappear. New diffraction peak is observed at $6.8^{\circ}$, being close to that of ZDS, indicating the complete formation of ZDS. According to the report of Dolgoplosk et al. [26], a basic salt is first formed by the reaction of SA and $\mathrm{ZnO}$. Then, the neutral salt is formed when the SA is excess. These two reactions could be described by Figure 2.
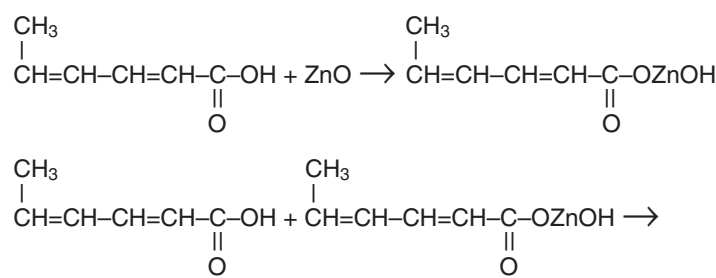

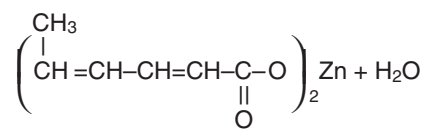

Figure 2. Reaction of $\mathrm{SA}$ and $\mathrm{ZnO}$

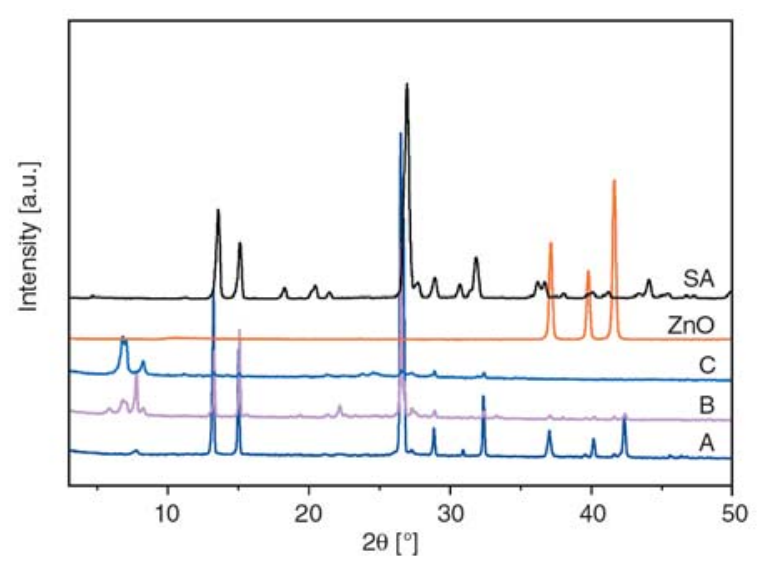

Figure 3. XRD patterns of $\mathrm{SA}, \mathrm{ZnO}$ and the three samples $\mathrm{A}, \mathrm{B}, \mathrm{C}$

It can be concluded that below $90^{\circ} \mathrm{C}$, only intermediate product showing a diffraction peak around $7.8^{\circ}$ is formed, and further heating to $120^{\circ} \mathrm{C}$ is necessary to obtain the ZDS completely. As a consequence, in the section below, we treated the rubber compounds at $120^{\circ} \mathrm{C}$ before the compression moulding and the results were compared with those without heat treatment.

The formation of ZDS during rubber vulcanization has been confirmed in our previous paper [19]. The same result was achieved in the present system. Figure 4 represents the XRD patterns of uncured rubber compounds with varying SA contents. It is shown that the intensities of the peaks at 22.76 and $27.66^{\circ}$, characterizing SA crystal, and the (100) and (101) diffractions of $\mathrm{ZnO}$ at 31.6 and $36.1^{\circ}$ are consistently increased with $\mathrm{SA}$ and $\mathrm{ZnO}$ loading. Except for these observations, there are no other changes in Figure 4, and the diffraction of ZDS is not observed, indicating that almost no ZDS is formed during the open mill compounding. How-

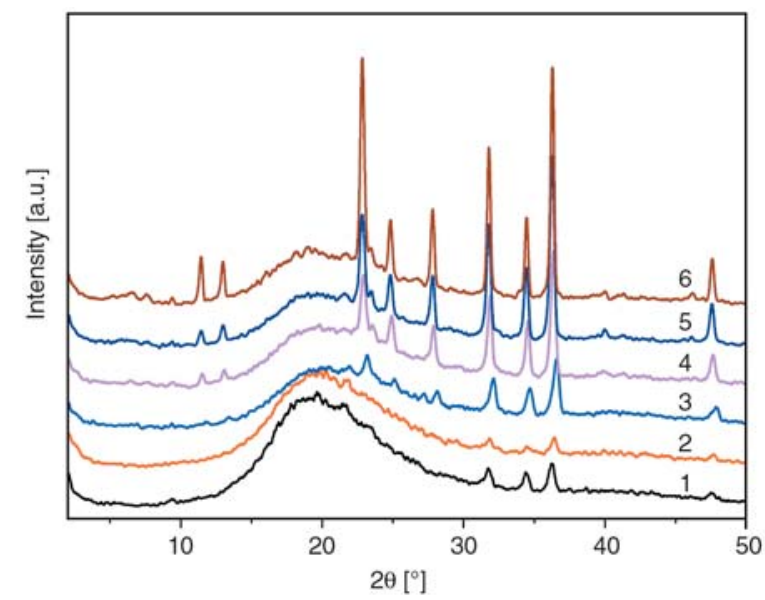

Figure 4. XRD patterns of uncured rubber compounds 


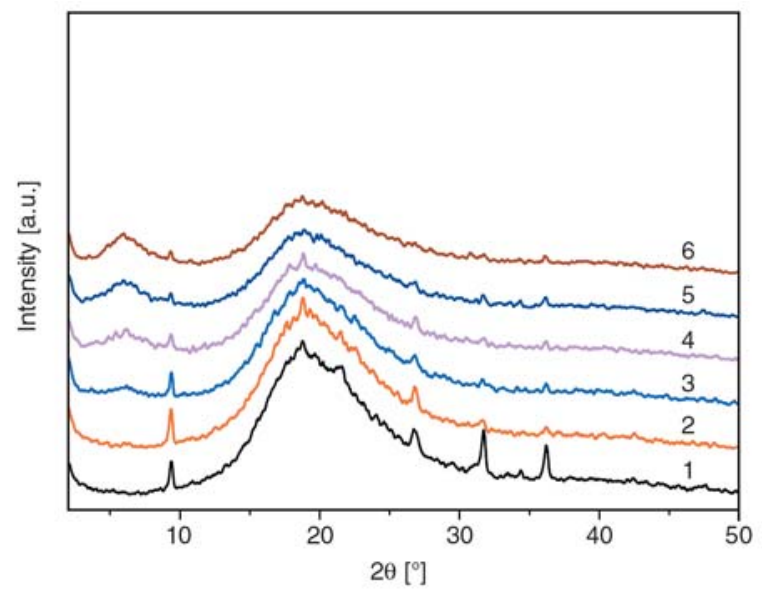

Figure 5. XRD patterns of rubber vulcanizates

ever, the reaction between $\mathrm{SA}$ and $\mathrm{ZnO}$ may take place during the vulcanization. As shown in Figure 5, which represents the XRD patterns of vulcanizates, the diffractions of $\mathrm{SA}$ and $\mathrm{ZnO}$ disappeared except for the control sample without SA. The reason is that $\mathrm{ZnO}$ reacted with SA during vulcanization. Consequently, it is believed that the compounding at ambient temperature is insufficient for the formation of ZDS and ZDS is predominately formed during vulcanization. The in situ formed ZDS could not survive as it undergoes polymerization under heating, therefore the diffractions for ZDS are not observed in the vulcanizates. We studied the polymerization of ZDS initiated by the free radical generated by the decomposition of DCP through DSC. We mixed the model compound $\mathrm{C}$ with $\mathrm{DCP}$, then sealed the mixture in DSC pan and heated to $200^{\circ} \mathrm{C}$ at $10^{\circ} \mathrm{C} / \mathrm{min}$, and the heat flow during heating was recorded, as can be seen in Figure 6. It is clear that there is a exothermic peak between 133 and $193^{\circ} \mathrm{C}$. It is believed that the

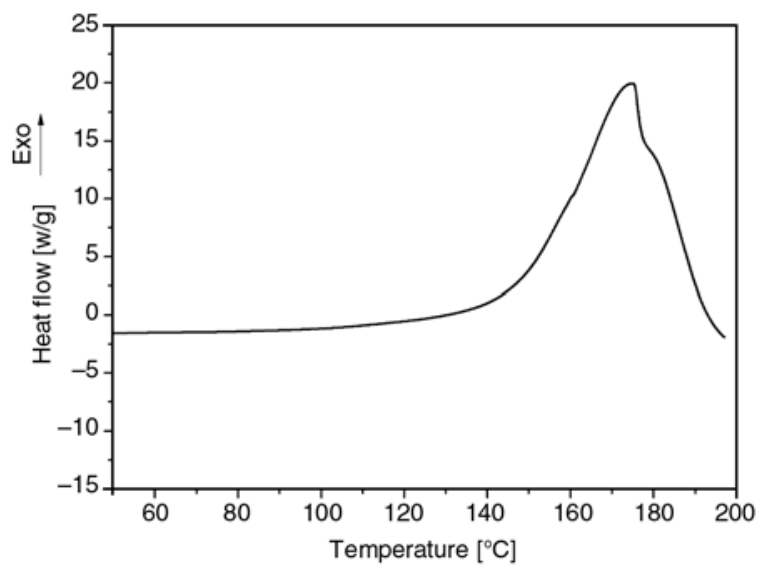

Figure 6. DSC graph of the ZDS/DCP mixture exothermic peak is due to the polymerization of ZDS and the enthalpy for the polymerization of ZDS is approximately $477.4 \mathrm{~J} / \mathrm{g}$.

Since $\mathrm{SA}$ is also reactive to rubber chains during vulcanization, the grafting of SA onto rubber chains is a competitive reaction to the formation of ZDS [27, 28]. To optimize the formation of ZDS in the rubber compounds, the open mill compounded rubber compounds excluding DCP were heat treated at $120^{\circ} \mathrm{C}$ for $15 \mathrm{~min}$. The XRD patterns of the heat treated rubber compounds are revealed in Figure 7. It is obvious that a new diffraction peak appears around $7.8^{\circ}$ when SA content is higher than 10 parts [phr]. The intensity of this peak is increased with the content of SA. The new diffraction can be assigned to the intermediate substance formed by the reaction of $\mathrm{ZnO}$ and $\mathrm{SA}$ as indicated above. This intermediate substance could be readily converted to ZDS upon further heating. The XRD patterns of the heat treated rubber vulcanizates are revealed in Figure 8. It is clear that after vulcaniza-

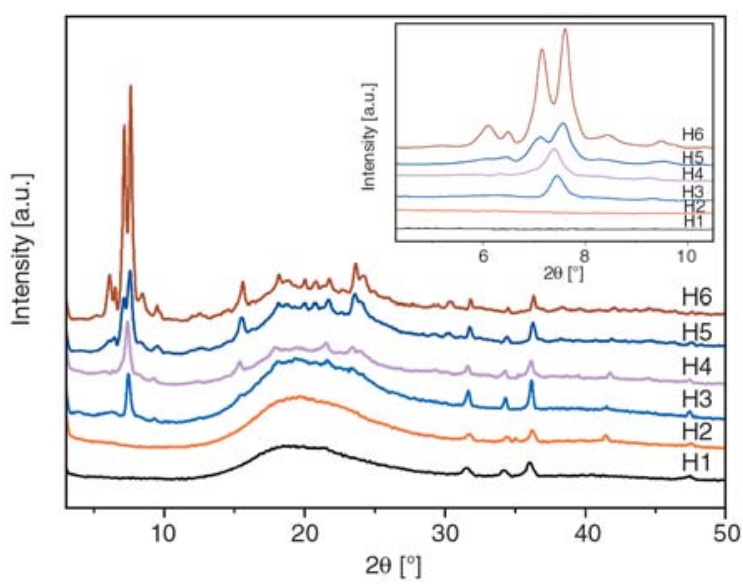

Figure 7. XRD patterns of the heat treated rubber compounds

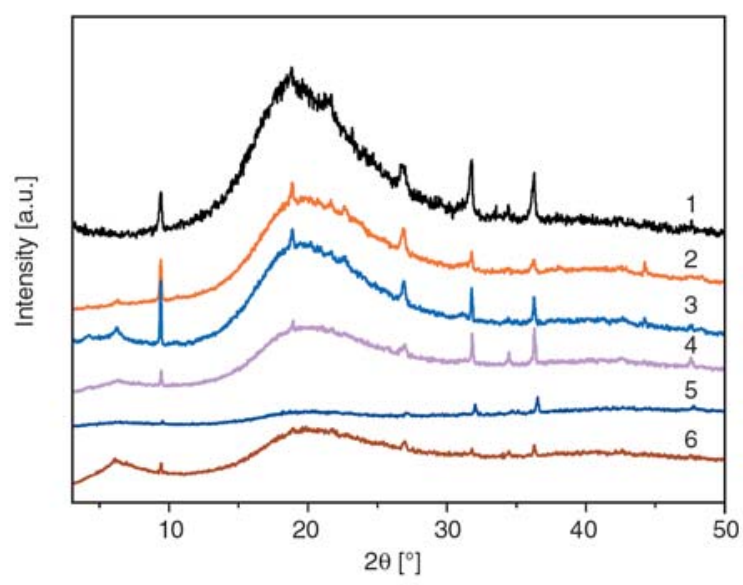

Figure 8. XRD patterns of the heat treated vulcanizates 


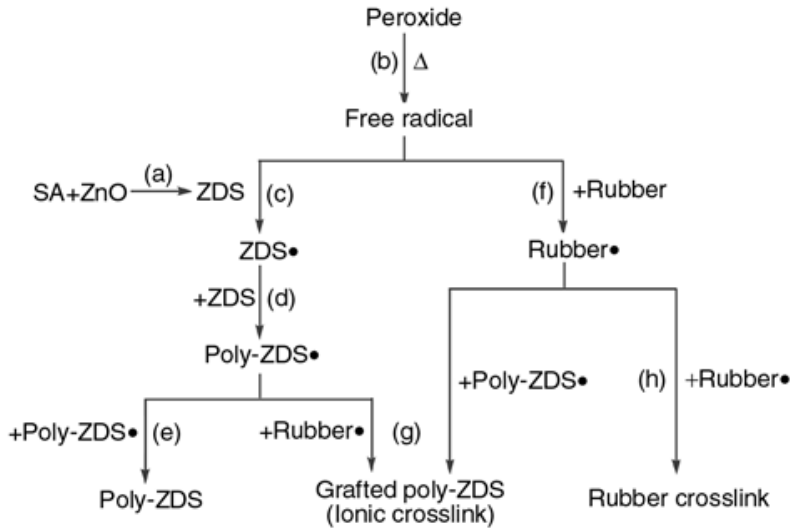

Figure 9. Possible reactions for NBR/SA/ZnO/DCP system

tion, the diffraction peaks of the intermediate substance are disappeared. However, the diffraction of ZDS could hardly be observed. It could be explained that during vulcanization, the intermediate substance is converted to ZDS, and the formed ZDS undergoes polymerization at the initiation of the free radical. The possible reaction pathways for the present system are illustrated in Figure 9. Reaction (a) represents the in situ formation of ZDS, including the formation of intermediate substance and its conversion to ZDS. Reaction (b) represents the generation of free radical by the decomposition of DCP. Reactions (c) and (d) represent the initiation of ZDS and chain growth of poly-ZDS. Reaction (e) represents the homopolymerization of ZDS by radical addition and termination by radical coupling. Reaction (f) represents the initiation of rubber chains. Reaction (g) represents the copolymerization of poly-ZDS and rubber chains, and the Reaction (g) will form ionic crosslink in the system. Reaction (h) represents the crosslink of the rubber chains.

\subsection{Curing characteristics of rubber compounds}

Figure 10 shows the vulcanization curves of the rubber compounds with different SA loading. As can be seen, the inclusion of SA leads to significant increase in the torque of compounds. The maximum torque of the compounds is consistently increased with the loading of SA. This may be due to reinforcement of ZDS particles and the strengthened interfacial interaction through the grafting of ZDS onto the rubber chains $[19,20]$. As also seen from

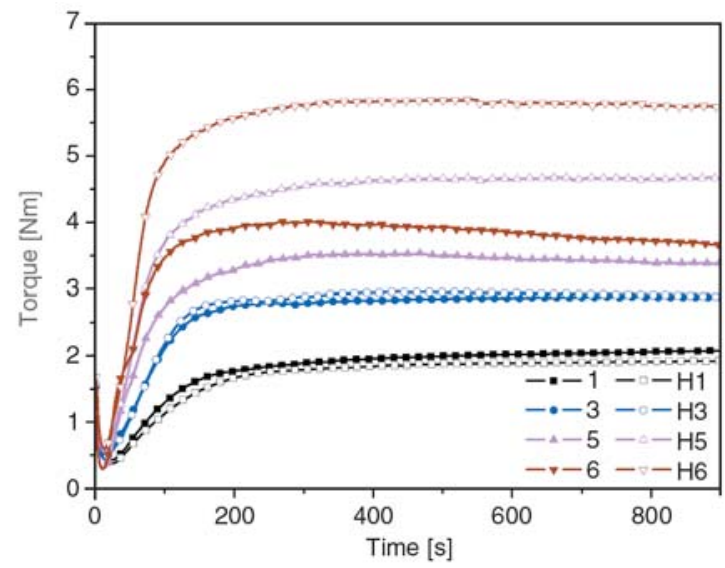

Figure 10. Comparison of the vulcanization curves of NBR/ZDS compounds with or without heat treatment

Figure 10, the increase of maximum torque with increasing SA content is also observed in the heat treated rubber compounds. When the SA content is lower than $10 \mathrm{phr}$, the difference between the torques of the rubber compounds with and without heat treatment is negligible. However, when the SA content is further increased, the torque of the compound with heat treatment is remarkably higher than that without heat treatment. This could be explained by the effectively increased ZDS content in the heat treated samples. When the open mill compounded sample is subjected to compression moulding, part of SA could not survive due to the radical polymerization and, as a consequence, the ZDS content is considerably lower than that with preheating before the compression moulding. The reinforcement of the rubber compounds is primarily contributed by the crosslinked ZDS particles, consequently the preheat compounds which possesses higher ZDS content show higher torque.

Figure 11 summarizes the scorch time $\left(T_{s 2}\right)$ and vulcanization time $\left(T_{c 90}\right)$ of the rubber compounds with different SA loading. As shown, the $T_{s 2}$ exhibits a slight decrease with increasing SA content. $T_{c 90}$ of the compound with SA is also lower than the control sample although its trend is not consistently decreasing with SA loading. It is noticeable that there are little changes in $T_{s 2}$ and $T_{c 90}$ after the preheating, suggesting the limited effect of the preheating on the scorch or curing time of the rubber compounds. The curing rate index (CRI), which indicates the rate of cure of the compounds, defined as (MH-ML)/( $\left.T_{c 90}-T_{s 2}\right)$, is summarized in Figure 12. ML and MH represent the 


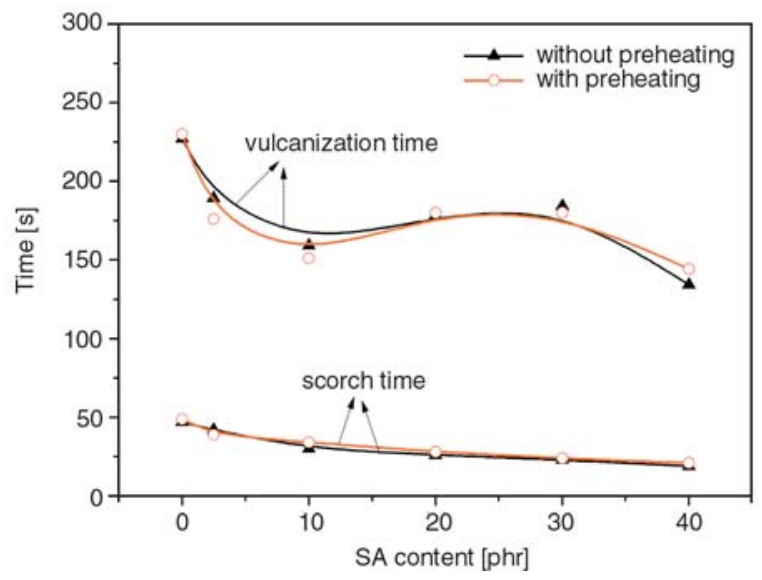

Figure 11. Vulcanization characteristics of NBR/ZDS compounds

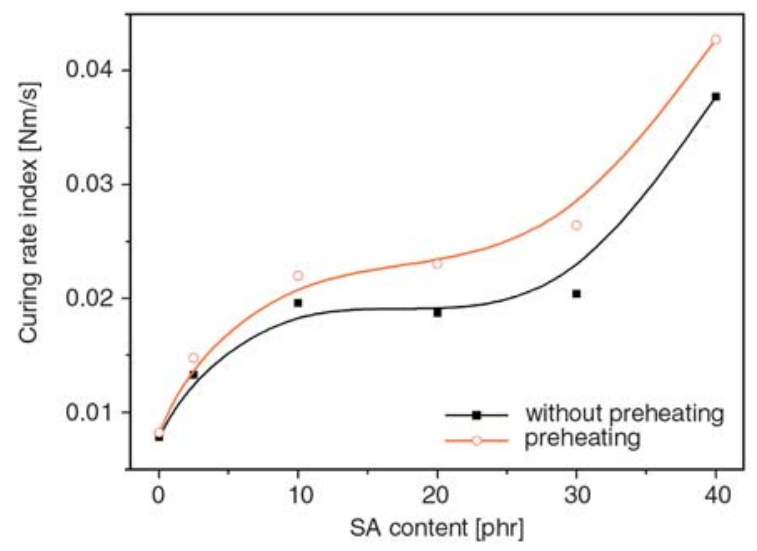

Figure 12. Curing rate index of NBR/ZDS compounds

minimum and maximum torque, respectively. A higher value of CRI means a higher rate of vulcanization. It can be seen that the value of CRI increases with the increasing of SA loading, indicating the acceleration of vulcanization by SA. And the heat treatment can further improve the curing rate. The CRI is mainly dependent on the crosslinking reactivity of the compound. The compound with higher ZDS content should have higher crosslinking reactivity as it can undergo crosslinking itself and the SA can only be linearly polymerized. Higher SA content or preheating on the uncured compounds are all beneficial to the formation of ZDS, consequently those samples show higher CRI values.

\subsection{Structure, morphology and mechanical properties of NBR vulcanizates with variable $S A$ content}

Table 2 summarizes the crosslink density of NBR vulcanizates with varying SA contents. The incre-
Table 2. Crosslink density of NBR vulcanizates with variable SA content (the data in the parenthesis is for the sample with preheating)

\begin{tabular}{|c|c|c|c|}
\hline & $\begin{array}{c}V_{e} \mathbf{1 0}^{-4} \\
{\left[\mathrm{~mol}^{-4} \mathrm{~cm}^{-3}\right]}\end{array}$ & $\begin{array}{c}V_{e 1} \mathbf{1 0}^{-4} \\
{\left[\mathrm{~mol} \cdot \mathrm{cm}^{-3}\right]}\end{array}$ & $\begin{array}{c}V_{e 2} \mathbf{1 0}^{-4} \\
{\left[\mathrm{~mol} \cdot \mathrm{cm}^{-3}\right]}\end{array}$ \\
\hline $1(\mathrm{H} 1)$ & $4.65(4.51)$ & $4.49(4.23)$ & $0.16(0.28)$ \\
\hline $2(\mathrm{H} 2)$ & $4.91(4.83)$ & $3.79(3.58)$ & $1.12(1.25)$ \\
\hline $3(\mathrm{H} 3)$ & $5.37(5.66)$ & $2.31(2.42)$ & $3.06(3.24)$ \\
\hline $4(\mathrm{H} 4)$ & $6.46(7.25)$ & $1.77(1.83)$ & $4.69(5.42)$ \\
\hline $5(\mathrm{H} 5)$ & $7.61(9.01)$ & $1.39(1.54)$ & $6.22(7.47)$ \\
\hline $6(\mathrm{H} 6)$ & $8.74(10.09)$ & $0.83(1.05)$ & $7.91(9.04)$ \\
\hline
\end{tabular}

ment in ionic crosslink density is indicative of the polymerization of ZDS during the vulcanization. From Table 2, it can be concluded that the total crosslink density $\left(V_{e}\right)$ and ion crosslink density $\left(V_{e 2}\right)$ are increased with SA, while the covalent crosslink density $\left(V_{e 1}\right)$ has the reverse trend.

The effect of preheating on the crosslink density of the vulcanization is also shown in Table 2. It is noticeable that the values of the $V_{e}$ and $V_{e 2}$ of the heat treated samples are higher than those of the vulcanizates without heat treated. The increase in the $V_{e 2}$ indicates more ZDS is formed in the preheated samples. Also, it is noticed that when SA content is more than $20 \mathrm{phr}, 75-90 \%$ of the crosslink is due to ionic crosslinks. The high content of ionic crosslinks is an indication of higher content of crosslinked ZDS, which is important for the reinforcement of the present systems.

TEM is used to study the morphology of the in situ formed and polymerized ZDS in NBR vulcanizates. Figure 13 shows the morphologies of the NBR/ ZDS composites with and without heat treatment. It clearly indicates that there are significant amount of nano-level dispersion, the darker phase, in TEM photographs of the ZDS/NBR composites with $8 \mathrm{phr}$ of $\mathrm{ZnO}$ and $20 \mathrm{phr}$ of SA investigated in this

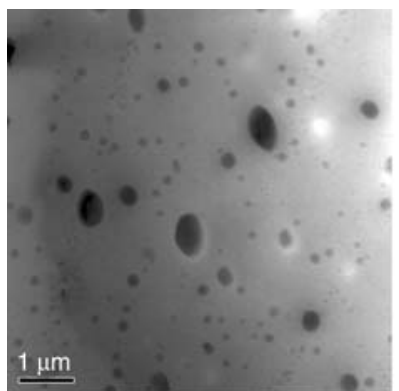

a)

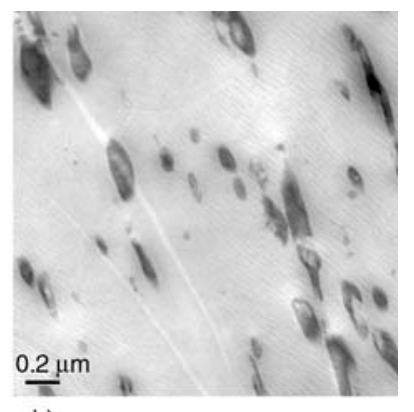

b)
Figure 13. Morphology of the NBR/ZDS composites (20 phr of SA and 8 phr of $\mathrm{ZnO}$ were included for both samples. left, without heat treatment; right, with heat treatment) 
Table 3. Mechanical properties of NBR vulcanizates with variable SA content (the data in the parenthesis is standard deviation)

\begin{tabular}{|c|c|c|c|c|c|c|}
\hline Sample code & $\begin{array}{c}\text { 100\% modulus } \\
\text { [MPa] }\end{array}$ & $\begin{array}{c}\text { Tensile strength } \\
{[\mathrm{MPa}]}\end{array}$ & $\begin{array}{c}\text { Shore A } \\
\text { hardness }\end{array}$ & $\begin{array}{c}\text { Tear strength } \\
{\left[\mathrm{kN} \cdot \mathbf{m}^{-1}\right]}\end{array}$ & $\begin{array}{c}\text { Elongation at break } \\
{[\%]}\end{array}$ & $\begin{array}{c}\text { Permanent set } \\
{[\%]}\end{array}$ \\
\hline 1 & $1.06( \pm 0.08)$ & $2.78( \pm 0.31)$ & 47 & $12.79( \pm 1.47)$ & $378.3( \pm 23.2)$ & 3 \\
\hline H1 & $1.04( \pm 0.02)$ & $2.82( \pm 0.21)$ & 47 & $12.94( \pm 1.16)$ & $392.5( \pm 10.7)$ & 3 \\
\hline 2 & $1.14( \pm 0.07)$ & $4.94( \pm 0.38)$ & 48 & $12.72( \pm 1.33)$ & $435.6( \pm 24.4)$ & 4 \\
\hline $\mathrm{H} 2$ & $1.07( \pm 0.03)$ & $5.95( \pm 0.56)$ & 48 & $18.53( \pm 1.04)$ & $499.1( \pm 25.7)$ & 6 \\
\hline 3 & $1.51( \pm 0.06)$ & $9.44( \pm 1.11)$ & 53 & $28.41( \pm 0.82)$ & $423.3 \quad( \pm 8.5)$ & 7 \\
\hline H3 & $1.75( \pm 0.07)$ & $11.89( \pm 1.11)$ & 54 & $32.56( \pm 2.12)$ & $461.5( \pm 25.2)$ & 8 \\
\hline 4 & $2.01( \pm 0.14)$ & $12.70( \pm 0.96)$ & 61 & $33.68( \pm 1.01)$ & $380.5( \pm 16.5)$ & 4 \\
\hline $\mathrm{H} 4$ & $2.92( \pm 0.06)$ & $16.08( \pm 1.21)$ & 66 & $42.75( \pm 1.02)$ & $403.3( \pm 12.3)$ & 6 \\
\hline 5 & $3.25( \pm 0.14)$ & $11.31( \pm 0.94)$ & 64 & $39.66( \pm 1.09)$ & $271.2( \pm 18.8)$ & 4 \\
\hline H5 & $4.81( \pm 0.18)$ & $15.73( \pm 1.51)$ & 75 & $45.41( \pm 1.66)$ & $324.1( \pm 21.9)$ & 6 \\
\hline 6 & $4.16( \pm 0.28)$ & $11.81( \pm 1.01)$ & 76 & $52.61( \pm 4.41)$ & $274.0( \pm 26.6)$ & 4 \\
\hline H6 & $3.76( \pm 0.08)$ & $15.64( \pm 0.93)$ & 83 & $66.18( \pm 0.59)$ & $276.0( \pm 13.3)$ & 4 \\
\hline
\end{tabular}

work. It can be judged that the small dark domains in the TEM photographs could represent the $\mathrm{Zn}$-rich regions, that is, the aggregates of poly-ZDS in the present system. The detailed mechanism of the formation of such inclusions in the rubber matrix, however, is still under investigation.

The reinforcing effect of in situ formed ZDS on NBR was summarized in Table 3. It is revealed that the $100 \%$ modulus, tensile strength, tear strength and shore A hardness are increased with SA content. For the SA included samples, the elongation at break is decreased with SA content. The incorporation of SA has little influence on the permanent set of NBR, and the value keeps at a low level for all the samples (below 10\%). What is more, the preheated samples have improved mechanical properties than those without preheating, and the more SA is added, the greater discrepancy in mechanical properties. Five to six fold increases in $100 \%$ modulus, tensile strength and tear strength are achieved compared with those of the control sample. It can be concluded that in situ formed ZDS shows promising reinforceablity towards NBR. Typical stressstrain curves are presented in Figure 14. One can see that low SA loading is beneficial to the increase in the elongation at break while higher loading SA is beneficial to improving the modulus and the strength of the NBR vulcanizate effectively.

The largely enhanced mechanical properties can mainly be explained as follows. When SA is incorporated, ZDS can be formed and crosslinked during rubber vulcanization. ZDS could also be grafted onto NBR chains and the interfacial bonding is enhanced. When low loading of SA is added, little

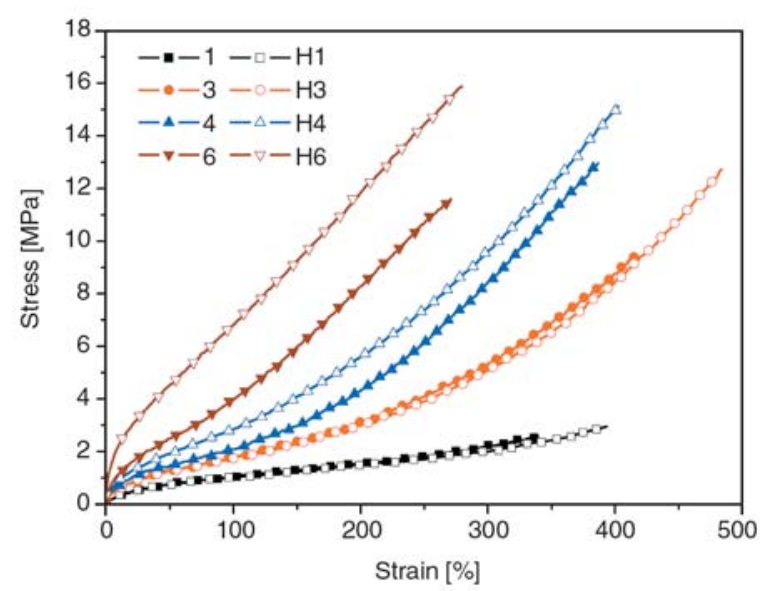

Figure 14. Typical stress-strain curves of NBR/ZDS vulcanizates

ZDS is formed and so the reinforcing effect is limited. At such a situation, the linear poly(sorbic acid) leads to the higher of the elongation at break and the increased permanent set. When large amount of SA is incorporated, most of SA could be converted to ZDS and therefore a crosslinked ZDS particle reinforced rubber network with excellent interfacial bonding is resulted. More ZDS is formed, higher reinforcement is observed in the systems. It is well documented that in situ formed zinc dimethacrylate acid has a significant reinforcement on rubbers $[9-13,17]$. Compared with the reported systems reinforced by the unsaturated metal carboxylates, although the increases in the mechanical performance do not surpass the previously reported ones, the present systems possess several advantages such as SA is a solid and edible substance with versatile reactivity and it is much cheaper than (meth)acrylic acid. 


\section{Conclusions}

The NBR compounds could be effectively reinforced by in situ formed ZDS through the reaction between $\mathrm{SA}$ and $\mathrm{ZnO}$ during rubber compounding. Limited ZDS was formed during open mill compounding and most of ZDS was formed during the vulcanization. Preheating on the uncured compounds prior to the vulcanization was effective in increasing the ZDS content. Incorporation of ZDS led to higher curing rate although the scorch time and vulcanization time were practically independent of the ZDS content. Inclusion of ZDS significantly increased the ionic bond content in the vulcanizates. The in situ formed ZDS showed promising reinforceability towards the NBR compounds. The modulus, tensile strength, tear strength and hardness were found to be increased consistently with the content of ZDS. Preheating of the compounds before the compression moulding was beneficial to the formation of ZDS, and consequently the increases in mechanical properties. At $40 \mathrm{phr}$ of SA and $16 \mathrm{phr} \mathrm{ZnO}$, five to six fold increase of tensile strength and tear strength of the neat NBR vulcanizate were achieved. The TEM results confirmed the nano-dispersion structure of the polymerized ZDS in the NBR matrix.

\section{Acknowledgements}

The authors thank the financial supports from the National Natural Science Foundation of China (50873035, 50933005), Guangdong Natural Science Foundation (151008901000137), Fundamental Research for the Central Universities (200922007) and National High-tech R\&D Program (863 Program, 2009AA03Z338).

\section{References}

[1] Payne A. R., Whittaker R. E.: Reinforcement of rubber with carbon black. Composites, 1, 203-214 (1970). DOI: $10.1016 / 0010-4361(70) 90005-4$

[2] Wagner M. P.: Reinforcing silicas and silicates. Rubber Chemistry and Technology, 49, 703-774 (1976).

[3] Bandyopadhyay A., Maiti M., Bhowmick A. K.: Synthesis, characterisation and properties of clay and silica based rubber nanocomposites. Materials Science and Technology, 22, 818-828 (2006).

DOI: $10.1179 / 174328406 \times 101265$
[4] Sadhu S., Bhowmick A. K.: Preparation and characterization of styrene butadiene rubber based nanocomposites and study of their mechanical properties. Advanced Engineering Materials, 6, 738-742 (2004). DOI: $10.1002 /$ adem.200400066

[5] Sato K.: Ionic crosslink of carboxylate SBR. Rubber Chemistry and Technology, 56, 942-958 (1983).

[6] Przybyszewska M., Zaborski M.: The effect of zinc oxide nanoparticle morphology on activity in crosslinking of carboxylated nitrile elastomer. Express Polymer Letters, 3, 542-552 (2009). DOI: $10.3144 /$ expresspolymlett.2009.68

[7] Costin R., Nagel W., Ekwall R.: New metallic coagents for curing elastomers. Rubber Chemistry and Technology, 64, 152-161 (1991).

[8] Costin R., Ekwall R., Nagel W.: Metallic coagent for curing elastomers. Rubber World, 206, 27-30 (1992).

[9] Nagata N., Sato T., Fujii T., Saito Y.: Structure and mechanical properties of hydrogenated NBR/zinc dimethacrylate vulcanizates. Journal of Applied Polymer Science: Applied Polymer Symposium, 53, 103 120 (1994).

[10] Yuan X. H., Peng Z. L., Zhang Y., Zhang Y. X.: The properties and structures of peroxide-cured NBR containing magnesium methacrylate. Polymers and Polymer Composites, 7, 431-436 (1999).

[11] Yuan X. H., Peng Z. L., Zhang Y., Zhang Y. X.: In situ preparation of zinc salts of unsaturated carboxylic acids to reinforce NBR. Journal of Applied Polymer Science, 77, 2740-2748 (2000).

DOI: $10.1002 / 1097-4628(20000919) 77: 12<2740:$ : AID-APP220>3.0.CO;2-X

[12] Peng Z. L., Liang X., Zhang Y. X., Zhang Y.: Reinforcement of EPDM by in situ prepared zinc dimethacrylate. Journal of Applied Polymer Science, 84, 1339-1345 (2002).

DOI: 10.1002/app.10112

[13] Yin D. H., Zhang Y., Zhang Y. X., Peng Z. L., Fan Y. Z., Sun K.: Reinforcement of peroxide-cured styrenebutadiene rubber vulcanizates by mathacrylic acid and magnesium oxide. Journal of Applied Polymer Science, 85, 2667-2676 (2002).

DOI: 10.1002/app.10641

[14] Yin D. H., Zhang Y., Peng Z. L., Zhang Y. X.: A comparison between the SBR vulcanizates reinforced by magnesium methacrylate added directly or prepared in situ. European Polymer Journal, 39, 99-105 (2003). DOI: 10.1016/s0014-3057(02)00171-4

[15] Sato T., Fujino A., Hayashi S., Oyama M., Ono K.: Simulation of crosslink and graft mechanism of hydrogenated-NBR/zinc di-methacrylate composites by moving die rheometer. Rubber Chemistry and Technology, 75, 943-954 (2002). 
[16]Lu Y. L., Liu L., Yang C., Tian M., Zhang L. Q.: The morphology of zinc dimethacrylate reinforced elastomers investigated by SEM and TEM. European Polymer Journal, 41, 577-588 (2005).

DOI: $10.1016 /$ j.eurpolymj.2004.10.019

[17] Lu Y. L., Liu L., Tian M., Geng H. P., Zhang L. Q.: Study on mechanical properties of elastomers reinforced by zinc dimethacrylate. European Polymer Journal, 41, 589-598 (2005).

DOI: $10.1016 /$ j.eurpolymj.2004.10.012

[18] Kaang S., Jin W., Kader M. A., Nah C.: Effects of blend composition and mixing method on mechanical and morphological properties of zinc dimethacrylatereinforced acrylonitrile-butadiene copolymer nanocomposites. Polymer-Plastics Technology and Engineering, 43, 1517-1538 (2004).

DOI: $10.1081 /$ PPT-200030263

[19] Guo B. C., Chen F., Lei Y. D., Liu X. L., Wan J. J., Jia D. M.: Styrene-butadiene rubber/halloysite nanotubes nanocomposites modified by sorbic acid. Applied Surface Science, 255, 7329-7336 (2009).

DOI: $10.1016 /$ j.apsusc. 2009.03.092

[20] Guo B. C., Chen F., Lei Y. D., Jia D. M.: Tubular clay composites with high strength and transparency. Journal of Macromolecular Science Part B: Physics, 49, 111-121 (2010).

DOI: $10.1080 / 00222340903346239$

[21] Guo B. C., Chen F., Lei Y. D., Chen W. W., Jia D. M.: Significantly improved performance of rubber/silica composites by addition of sorbic acid. Polymer Journal, 42, 319-326 (2010). DOI: $10.1038 /$ pj.2010.4
[22] Flory P. J., Rehner J. J.: Statistical mechanics of crosslinked polymer networks. II. swelling. Journal of Chemical Physics, 11, 521-526 (1943).

DOI: $10.1063 / 1.1723792$

[23] Flory P. J.: Statistical mechanics of swelling of network structures. Journal of Chemical Physics, 18, 108-111 (1950). DOI: $\underline{10.1063 / 1.1747424}$

[24] Shvarts A. G.: Evaluation of rubber-solvent interaction. Rubber Chemistry and Technology, 31, 691-698 (1958).

[25] Sheehan C. J., Bisio A. L.: Polymer-solvent interaction parameters. Rubber Chemistry and Technology, 39, 149-192 (1966).

[26] Dolgoplosk B. A., Tinyakova E. I., Reikh V. N., Zhuravleva T. G., Belonovskaya G. P.: Carboxylic rubbers. I. Synthesis and structures. Rubber Chemistry and Technology, 32, 321-327 (1959).

[27] Kataoka S., Ando T.: Asymmetric induction in radical polymerization of sorbic acid in the presence of chitosan (in Japanese). Kobunshi Ronbunshu, 37, 375382 (1980).

[28] Matsumoto A., Oshita S., Fujioka D. A.: A novel organic intercalation system with layered polymer crystals as the host compounds derived from 1,3-diene carboxylic acids. Journal of the American Chemical Society, 124, 13749-13756 (2002). DOI: $10.1021 / \mathrm{ja} 020869 \mathrm{c}$ 